\title{
Influence of the Soil-Structure Interaction on the Design of Steel-Braced Building Foundation
}

\author{
Alireza Azarbakht ${ }^{\mathrm{a}}$ and Mohsen Ghafory Ashtiany ${ }^{\mathrm{b}}$ \\ ${ }^{a}$ Assistant Professor, Department of Civil Engineering, Arak University, Arak, Iran 38156-879. \\ Email: a-azarbakht@araku.ac.ir \\ ${ }^{b}$ Professor, International Institute of Earthquake Engineering and Seismology, (IIEES), Tehran, Iran. \\ Email: ashtiany@iiees.ac.ir
}

\begin{abstract}
The modeling and analysis of the superstructure and the foundation for the seismic lateral loads are traditionally done separately. This assumption is an important issue in the design/rehabilitate procedures especially for the short period structures, i.e. steel braced or shear wall systems, which may result to a conservative design. By using more advance procedures, i.e. nonlinear static method, and the incorporation of the soil-structure interaction (SSI), the seismic demand in the lateral resisting system decreases and the design will become more economic. This paper includes an investigation about the influence of the SSI effect on the design of the steel-braced building foundation. The presented example is a three-bay three-storey steel braced frame. Three design methods based on the FEMA 356 guideline and the UBC 97 code are taken in to consideration. The three methods are: (1) linear static analysis based on the UBC 97 code assuming the fixed based condition; (2) linear static analysis based on the FEMA 356 guideline assuming the fixed based condition; and (3) nonlinear static analysis assuming both fixed and flexible based assumptions. The results show that the influence of the SSI on the input demand of the short period building foundations is significant and the foundation design based on the linear static method with the fixed base assumption is so conservative. A simple method is proposed to take the SSI effect in to consideration in the linear static procedure with the fixed base assumption, which is a common method for the engineers. The advantage of this proposed method is the simplicity and the applicability for the engineering purposes.
\end{abstract}

Keywords: soil-structure interaction, FEMA 356, UBC 97, foundation, fixed base, flexible base.

\section{INTRODUCTION}

The actions for the design of foundation are defined to be force-controlled based on the FEMA 356 guideline [4]. It means that the total seismic lateral force shall be reduced by the factor of $C_{1} C_{2} C_{3} J$ and should be combined with the gravity load effects (Equation 3-21 of [4]). The $J$ is the force-delivery reduction factor. The resultant force shall be compared with the element resistance considering the lower bound material properties and the partial safety factors equal to the unity. In other words, the ultimate force is compared with the lower bound of the resistance.

It worth to compare the seismic base shears based on the FEMA 356 guideline and a well known design code such as UBC 97 code [6]. The comparison result is shown in Equation (1). The Equation (1) is derived for the structures with the fundamental period greater than $T_{0}$, where $T_{0}$ is the period at which the constant acceleration region of the design response spectrum begins. The structures, with shorter natural periods 
less than $T_{0}$, are not in this paper's context. For clarify of exposition, we can consider an ordinary steel braced frame ( $R=5.6$ ), which is a school building ( $I=1.25)$, located in a high seismic zone (Tehran, Iran, $Z=0.4$ ) and the soil type of $S_{c}$. The total ultimate base shear for the structure based on the UBC 97 code [6] and the force-controlled base shear based on the FEMA 356 guideline [4] are equalized to derive the Equation (1). The only difference will remain in the resistance side, where the partial safety factors are equal to the unity in FEMA 356 guideline [4] but it is less than one in the case of design codes, i.e. UBC 97 code [6]. This difference in the resistance side does not mostly affect on the final results, because the final conclusion strongly depends on the foundation uplift rather than the resistance partial safety factors.

$$
\frac{C_{v} I}{R T} W=\frac{C_{1} C_{2} C_{3} C_{m} S_{a}}{C_{1} C_{2} C_{3} J} W \Rightarrow J=\left\{\begin{array}{lll}
\left(\frac{T}{T_{s}}\right) \frac{C_{m} R}{I} & \text { for } \quad T_{0} \leq T \leq T_{s} \\
\frac{C_{m} R}{I} & \text { for } \quad T>T_{s}
\end{array}\right.
$$

where $C_{m}$ is the effective mass factor, $I$ is the importance factor, $C_{v}$ is the seismic coefficient, $R$ is the numerical coefficient representative of the inherent overstrength and global ductility capacity of lateral force-resisting system, $T$ is the elastic fundamental period of vibration, $T_{s}$ is the period at which the constant acceleration region of the design response spectrum ends and $S_{a}$ is the spectral response acceleration at the fundamental period of structure.

For the illustrated example in the paper, the $J$ factor can be written as Equation (2).

$$
J=\left\{\begin{array}{lll}
\left(\frac{0.36}{0.56}\right) \frac{0.9 \times 5.6}{1.25}=2.59 & \text { for } \quad T_{0} \leq T \leq T_{s} \\
\frac{0.9 \times 5.6}{1.25}=4.03 & \text { for } \quad T>T_{s}
\end{array}\right.
$$

In means, the above values for the $J$ factor are implicitly used in the design code. On the other hand the FEMA 356 guideline [4] recommends $J=2$ for the high seismic zones which is obviously less, at least with the prescribed assumptions, than the values that is implicitly used in the design procedures (as derived in Equation (2)). Thus, the foundation based on the design codes (e.g., UBC 97 code [6]) may be vulnerable based on the rehabilitation guidelines (e.g., FEMA 356 guideline [4]). In other words, the assessment of the foundation based on the FEMA 356guideline [4], at least for the linear static procedure with the fixed base assumption, is so conservative. This conclusion is not correct, if the movement of the base (soil-structure interaction) is taken in to account. The fixed-base modeling assumption is inappropriate for many structures though [2]. Structural systems that incorporate stiff vertical elements for lateral resistance (e.g., shear walls, braced frames) can be particularly sensitive to even small base rotations and translations that are neglected with a fixed base assumption [2]. This problem is reported also in FEMA 357, "overturning calculations at pseudo lateral force levels appear to be overly conservative and can predict overturning stability problems that are not well correlated with observed behaviour" [3]. 


\section{METHODOLOGY AND TEST STRUCTURE}

A reference structure is selected which is an existing school located in Tehran, Iran. For the purpose of simplicity, one of the three braced frames, that is shown in Figure (1), in the shorter direction of the school plan is chosen for the two-dimensional analysis. It is assumed that one third of the seismic lateral load is carrying by this braced frame. The storey height is equal to 340 centimeter and the outer and the inner bays length are, respectively, equal to 600 centimeter and 360 centimeter. The diaphragms are assumed to be rigid. The allowable soil stress under foundation is $1.7 \mathrm{~kg} / \mathrm{cm}^{2}$. The frame view is shown in Figure (1).

The braced frame is designed/checked using the below conditions:

1- $\quad$ The existing frame is checked for the combination of gravity and seismic load based on the UBC 97 code [6]. It is assumed that the base is fixed and the linear static procedure is used.

2- $\quad$ The frame is rehabilitated using UBC 97 code [6]. The fixed base assumption as well as the linear static procedure is used.

3- $\quad$ The frame is rehabilitated using FEMA 356 guideline [4]. Both of the fixed base and the flexible based assumptions are used in combination with the linear static and non-linear static procedures.

4- $\quad$ A simple method is proposed for the foundation design to avoid from the prescribed conservation.

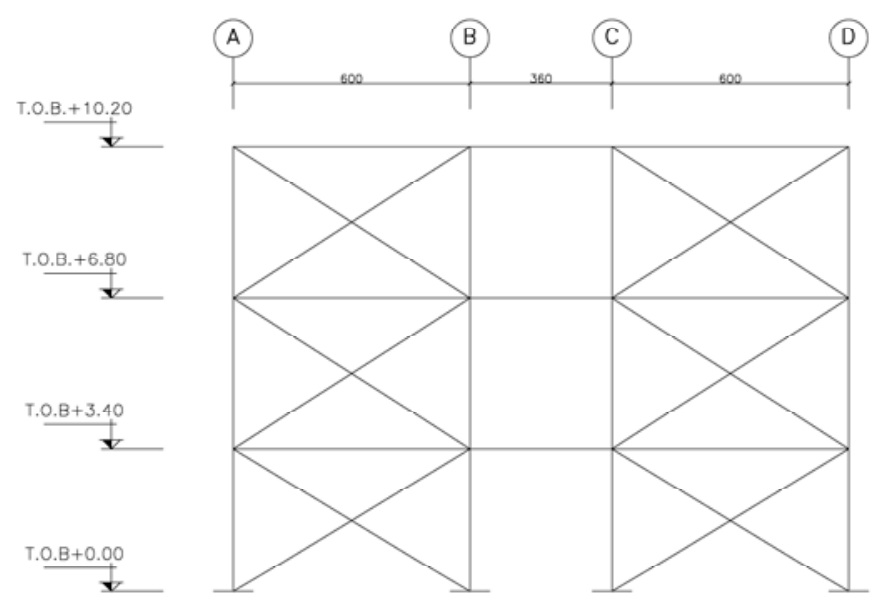

FIGURE 1. The elevation of the frame under investigation.

\section{PROPOSED METHOD}

The use of $R_{O T}$ is proposed as an alternative method for the assessment of the overturning effect as well as the soil pressure checking in FEMA 356 guideline [4]. The alternative procedure is intended to provide a method that is consistent with prevailing practice specified in current codes for new buildings [4]. On the other hand, the allowable foundation and lateral pressures, in the design code, shall be checked using the allowable stress load combinations (Section 1805 of [6]). It means that the 
use of $R_{O T}$ in FEMA 356 guideline [4] can be interpreted as the allowable stress design force combinations in the design codes (e.g., reference [6]). The seismic lateral force for the ultimate strength design is 1.4 times of the allowable stress design force (compare sections 16.12.2 and 16.12.3 of reference [6]). Hence, 1.4 times of the combinations corresponding to the force-controlled seismic forces, by substituting the $J$ factor by $R_{O T}$ factor, are reasonable choices for the design of the foundation. The seismic lateral force can be simply combined with the gravity load effects as shown in Equation (3).

$$
\mathrm{Q}_{\mathrm{UF}}=Q_{G} \pm 1.4 \times \frac{Q_{E}}{C_{1} C_{2} C_{3} R_{O T}}
$$

where $Q_{G}$ is the gravity force and $1.4 \times \frac{Q_{E}}{C_{1} C_{2} C_{3} R_{O T}}$ is the seismic lateral force corresponding to the ultimate strength design. The results, which are explained in the next section, confirm that the use of the proposed force combinations results to the much more reasonable aspects for the design of foundation.

\section{RESULTS USING DIFFERENT METHODS}

The frame is designed using four different procedures. The results, as shown in Figure (2), are categorized for the analysis, substructure and superstructure parts. In the analysis part, the natural period of the structure, the design base shear, the overturning moment and the roof displacement are presented. The natural period of the vibration is equal to 0.57 second in the case of the flexible base condition which is $58 \%$ greater than the empirical value corresponding to the design code. This means the $J$ factor can be taken, at least, equal to 4 based on the Equation (2). The base uplift is a function of the gravity loads as well as the foundation overturning moment. Thus, the influence of the foundation overturning moment on the design procedure is more important than the base shear. For example, the foundation overturning moment is a little bit less than the value corresponding to the nonlinear static case with the flexible based assumption; however, the design results are in the same order.

In the substructure part, as explained in Figure (2), the overturning safety factor is calculated with two different methods. The method 1 and 2 are, respectively, based on the $J$ and $R_{O T}$ factors. The soil pressure safety factor, the maximum design compressive reactions in the A and B axis, see Figure (1), and the rehabilitated foundation results are shown in this part. The designed foundation based on the design code is vulnerable based on the linear static procedure with the fixed based assumption. However, the foundation based on the nonlinear static procedure is more economic.

In the superstructure part, the bracing sections as well as the average columns area in each story is presented. The design elements are, obviously, more economic by implementing more advanced procedures, i.e., nonlinear static procedure with flexible based assumption. The designed frame is the same as the frame in the linear static procedure with the fixed base assumption, but, the foundation is approximately similar to the foundation of the nonlinear static case with the flexible based assumption. 


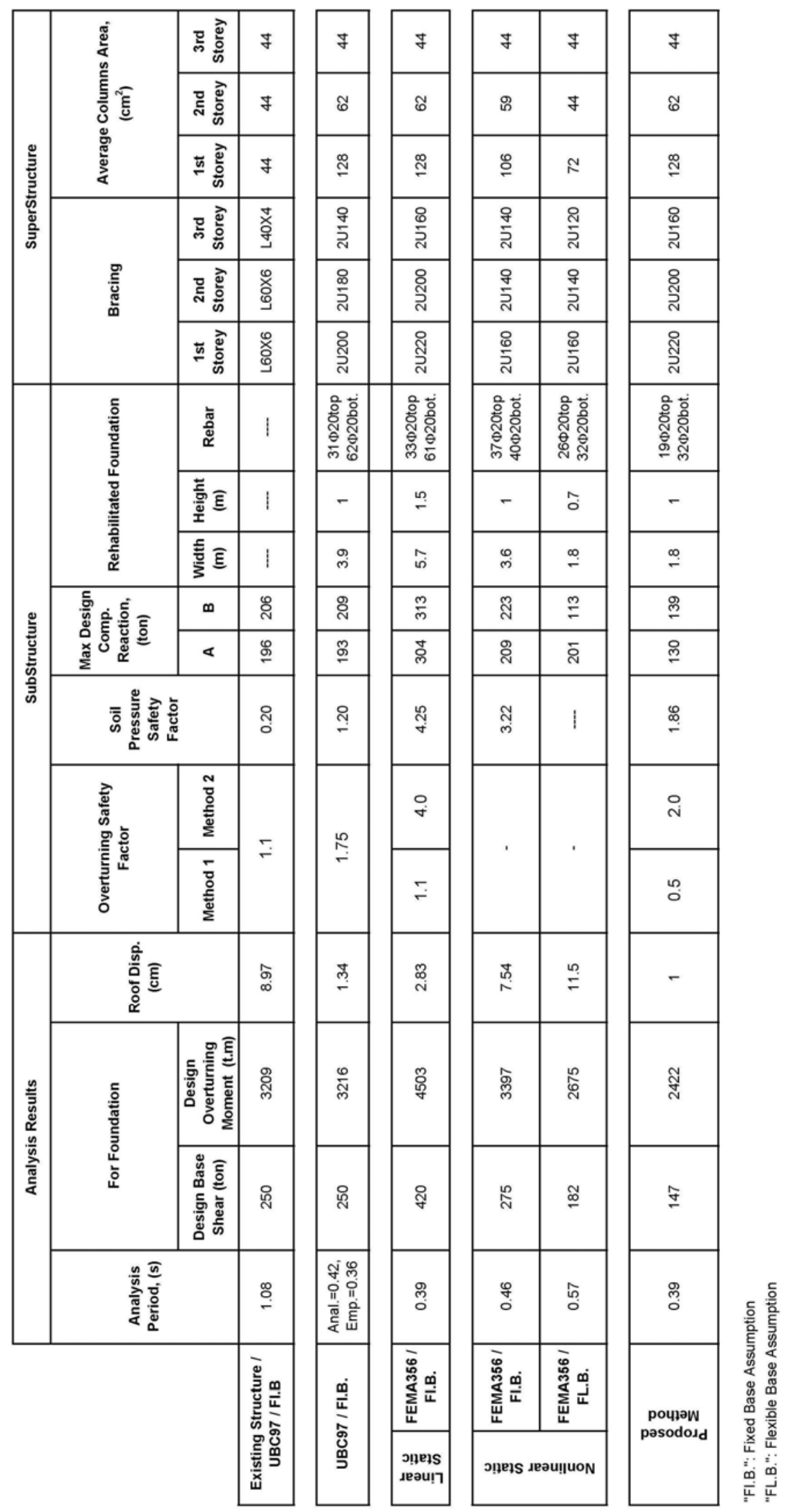

FIGURE 2. The results of the existing and the rehabilitated structure using different methods. 


\section{THE NONLINEAR STATIC ANALYSIS RESULTS}

The frame is rehabilitated, in the last section, using the nonlinear static procedure considering the fixed base and the flexible base assumptions. The comparison of the pushover curves and the corresponding target displacements are shown in Figure (3). In the case of flexible based assumption, the target displacement is greater and the input base shear is less than the case of the fixed base assumption. This effect comes from the base flexibility which elongates the structural natural period of vibration and obviously decreases the seismic demand.

The frames (superstructure) which are designed by the four different methods, as explained in Table (1), are analyzed using the nonlinear static procedure once considering the fixed based assumption and second using the flexible based condition. The input base shears for the four frames, as shown in the left graph in Figure (4), are different. But, by using the flexible base assumption, as shown in the right graph in Figure (4), the difference in the base shears becomes practically negligible for all of the structures.

Another interesting fact is that, the frames which are designed based on FEMA 356 guideline [4] using the linear static procedure with the fixed based assumption as well as the nonlinear static procedure with the flexible based assumption cannot satisfy the acceptance criteria, if the nonlinear static procedure with the fixed base assumption is utilized. This fact makes an inconsistency between the different rehabilitation procedures in the FEMA 356 guideline [4]. However, the frames which are designed by any procedure with the fixed based assumption will satisfy the acceptance criteria, if the same procedure with the flexible based assumption is used, as seen in Figure (4).

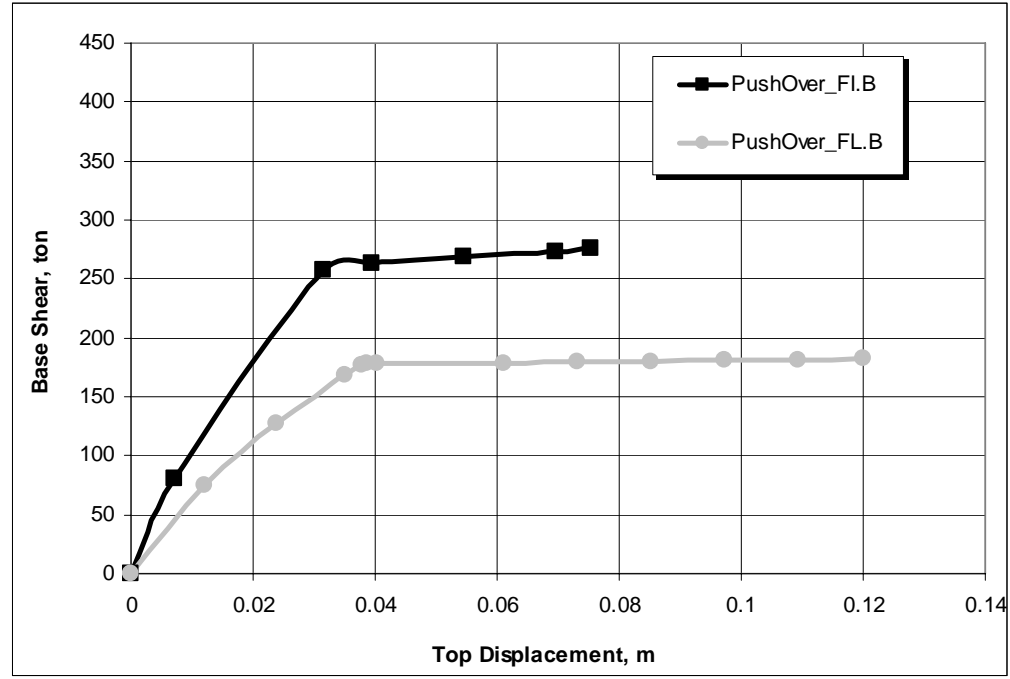

FIGURE 3. The comparison of the nonlinear static curves (and the corresponding target displacements) for the structures designed by the nonlinear static analysis assuming both the fixed and the flexible based assumptions. 

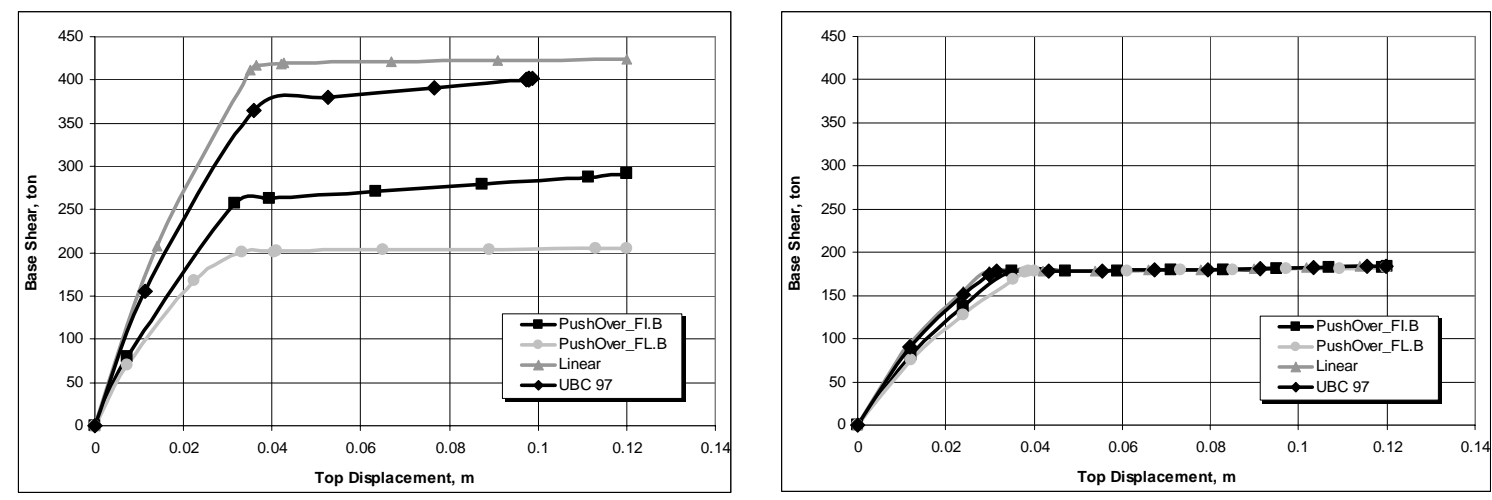

FIGURE 4. The comparison of the nonlinear static curves for the structures which are designed by the four different methods, (Left): fixed based assumption and (Right): flexible based assumption.

\section{CONCLUSION}

The design or rehabilitation of foundation, for the structures with stiff lateral resisting systems using the linear static procedure with the fixed based assumption, results to a relatively conservative design. By taking the soil-structure-interaction in to account, the seismic demand decreases and the foundation design will be more economic.

A simple procedure is proposed to modify the design of foundation in the linear static procedure with the fixed based assumption within the FEMA 356 guideline [4]. The proposed method is based on the philosophy of the alternative method for the overturning control which is available in the guideline. It is shown that the foundation design based on the proposed procedure is economic without explicitly taking the base flexibility in to consideration.

\section{REFERENCES}

1. AISC. Allowable Stress Design Manual of Steel Construction. American Institute of Steel Construction, Inc. Chicago, IL (1989a).

2. FEMA. Improvement of Nonlinear Static Seismic Analysis Procedures. Report No. FEMA-440, Federal Emergency Management Agency, Washington, DC, (2005).

3. FEMA. Global Topics Report on the Prestandard and Commentary for the Seismic Rehabilitation of Buildings. Report No. FEMA-357, Federal Emergency Management Agency, Washington, DC, (2000).

4. FEMA. Prestandard and commentary for the seismic rehabilitation of buildings. Report No. FEMA356, Federal Emergency Management Agency, Washington, DC, (2000).

5. FEMA. NEHRP Commentary on the Guidelines for the Seismic Rehabilitation of Buildings. Report No. FEMA-274, Federal Emergency Management Agency, Washington, DC, (1997).

6. UBC 97. Uniform Building Code. International Conference of Building Officials, 5360 Workman Mill Road Whittier, California, 90601-2298, (1997). 